\title{
Verklarende woordelys vir die orde Branchiura
}

\author{
A. Avenant* en J.G. van As \\ Randse Afrikaanse Universiteit, Posbus 524, Johannesburg 2000 \\ G.C. Loots \\ Potchefstroomse Universiteit vir Christelike Hoer Onderwys, Potchefstroom 2520
}

Die toenemende belangstelling in varswater akwakultuur in Suidelike Afrika is vir die studie van visparasiete belangrik. Verskeie navorsingsprojekte oor een of ander aspek van die biologie van die Branchiura is gedurende die tagtiger jare aangepak. Hierdie navorsing het behoefte aan standaard Afrikaanse terme, wat spesifiek op die Branchiura van toepassing is, laat ontstaan.

Die orde Branchiura (Crustacea) sluit slegs een familie in, naamlik die Argulidae, waarvan vier genera bekend is; d.i. Argulus, Müller, 1785, Chonopeltis, Thiele, 1900, Dipteropeltis, Calman, 1912 en Dolops, Audouin, 1837. Hiervan is die genus Argulus die grootste met meer as 'n honderd bekende spesies waarvan 21 in Afrika voorkom.' Hierdie genus bevat sowel mariene- as varswaterlewensvorme. Die genus Chonopeltis is endemies aan Afrika en daar is reeds 11 spesies bekend, terwyl slegs een spesie van die genus Dipteropeltis tot dusver bekend is. ${ }^{3}$ In die genus Dolops is daar nege spesies in SuidAmerika, een in Tasmanie en een in Afrika bekend. ${ }^{2}$ Laasgenoemde drie genera is almal uitsluitlik varswatergenera.

Alhoewel die Branchiura visparasiete is, noem Ringuelet dat 'n verteenwoordiger van die Branchiura ook op 'n alligator in 'n akwarium in New York gevind is ${ }^{3}$ en dat Stuhlmann Dolops ranarum op paddavisse gevind het. ${ }^{4}$

Met die woordelys wat hier aangebied word, word daar nie gepoog om standaardterminologie te herdefinieer nie, maar eerder om aan te dui hoe dit in hierdie groep organismes aangewend word. Derhalwe word figure gebruik om spesifieke strukture aan te dui. Engelse terme word, waar dit bestaan, ook verskaf. Morfometriese eienskappe wat in die taksonomie van die Branchiura gebruik word, word ingesluit, asook standaardbesmettingstatistieke-terminologie.

Abdomen: abdomen (Ab - Fig. 1, 2, 3\& 4)

Die posterior tagma van die liggaam. By mannetjies word die testis en by wyfies die spermatekas hier aangetref.

Abdomenbreedte (G - Fig. 14)

Die afstand gemeet oor die breedste deel van die abdomen.

Abdomenlengte ( $F$ - Fig. 14)

Die afstand tussen die verbinding van die vierde torakaalsegment met die abdomen en die abdomen- punte. Die afmeting word oor die kortste moontlike afstand gemaak.

Abdomenlobbe: abdominal lobes (Abl - Fig. 1, 2, 3

\& 4)

Uitsteeksels van die abdomen aan weerskante van die abdomenspleet.

Abdomenspleet: abdominal split/anal split (J - Fig. 14)

Die spleet tussen die twee lobbe van die abdomen.

Abdomenspleetlengte: abdomen split (J - Fig. 14)

Die lengte van hierdie spleet word verkry deur die afstand vanaf die anusopening tot by die posteriorpunt van die abdomen oor die kortste moontlike afstand te meet.

Antenne (2de antenne): antenna (Ant - Fig. 1, 3, 4 \& 9)

Tweede aanhangsel aan die sefalon. By alle bekende spesies is dit lank en dun.

Antennule (1e antenne): antennule/first antenna (Antl - Fig. 1, 3 \& 9)

Eerste aanhangsel aan die sefalon. Podomere versmelt om 'n haak te vorm, maar is afwesig by volwasse Chonopeltis-indiwidue.

Anterior antennulestekel: anterior spine/anterior knob (Aant - Fig. 9)

Antennulestekel aan die anteriorkant van die antennule.

Basaalplaat: scabrous area/basal plate (Bpl - Fig. 1, $3 \& 4)$

Chitienplaat met of sonder skubbe en stekels op die proksimaalpodomeer van die maksilla.

Basaal podomeer/eerste podomeer/basispodomeer

Die podomeer waaruit die aanhangsel ontstaan (d.i. die koksapodiet)

Basaalstekels: basal spine/lamina (Bst - Fig. 1 \& 3) Uitsteeksel op posteriorrand van proksimaalpodomeer (basaalplaat - Bpl) van die maksilla.

Besmettingsmoontlikhede (BM): Abundance/relative density.

Die moontlikheid vir enige gasheer in 'n bevolking om met ' $n$ parasiet besmet te raak. Dit word bereken deur die aantal parasiete (p) wat vanaf die steekproefgashere (n) versamel is, uit te druk as:

$$
\mathrm{BM}=\frac{\mathrm{P}}{\mathrm{n}}
$$

Dit kan ook bereken word deur

$$
\mathrm{GBI} \times \% \mathrm{~B}=\mathrm{BM}
$$


of deur die besmettingsfaktor (B) te gebruik (voordat die persentasie bereken is):

$$
\mathrm{GBI} \times \mathrm{B}=\mathrm{BM}
$$

Om B te bereken kyk persentasie besmetting.

Besmettingstatistiek: ecological parasitology/ parasitological terms

Kyk besmettingsmoontlikheid, besmettingsintensiteit en persentasiebesmetting.

Bevrugtingskamer

Ruimte wat by die wyfie gevorm word tussen die abdomen en swemlobbe wanneer die swemlobbe plat teen die liggaam gehou word.

Chitienpen: peg ( $\mathrm{P}-$ Fig. 11)

Pen versterk met chitien, vorm deel van die pen-enkoker-struktuur. Kom voor op die vierde swempoot van Argulus- en Chonopeltis-indiwidue. By Dolopsindiwidue word slegs 'n pen (op die derde swempoot) aangetref. Kyk ook koker.

Dorsaalrif: dorsal ridge/rib (Dr - Fig. 2)

Chitienversterking op dorsaalkant van sefalon. By

Chonopeltis van taksonomiese belang.

Eierdraend: gravid

'n Wyfie waarvan die eiersak met eiers gevul is.

Eierpakkie: cluster of eggs

'n Groepie eiers, op een plek, deur een wyfie gelê. Een wyfie kan opeenvolgend meer as een eierpakkie produseer.

\section{Eiersak}

Kyk uterus.

Eksopodiet: exopodite (Ek - Fig. 1, 2 \& 4)

Distaal (laterale) ramus van die twee-assige swempoot.

Endopodiet: endopodite (En - Fig. 1, 2 \& 4)

Distaal (mediale) ramus van die twee-assige swempoot.

Enkelvoudige oog/nauplius oog/mediaanoog: nauplius eye/median eye/median ocellus ( Na - Fig. 2)

Enkele mediaanoog, bestaan uit een of meer ligsensitiewe selle.

Flabellum: flabellum (Fl - Fig. 10)

Kyk ook flagellum (I)

Hierdie term is verkeerdelik gebruik om die flagellum aan die basipodiet van die swempote van Argulus te beskryf. 'n Flabellum is egter die epipodiet en kom dus op die basaalpodomeer (koksapodiet) voor.

Flagellum (I): flagellum/hair

Kyk ook flabellum en flagellum II

Mediaangerigte uitgroeisel aan die dorsaalkant van die eerste twee paar swempote. Dit is by sommige Dolops-spesies ook op die derde swempoot aanwesig. By Argulus staan dit verkeerdelik bekend as flabellum.

\section{Flagellum (II): Flagellum}

Terminale (distale) gedeelte van die antenne.

Furkaalrami: furcal rami/abdominal papilla

Papille op die abdomen. Die posisie van die papille is binne die genus Dolops van taksonomiese belang. 'n Aantal seta kom op die papille voor.
Gemiddelde besmettingsintensiteit (GBI) = intensity Dui aantal parasiete per besmette indiwidu aan. Bereken getal parasiete (p) versamel, gedeel deur getal besmette gashere (b)

$$
\mathrm{GBI}=\frac{\mathrm{P}}{\mathrm{b}}
$$

Grypend: prehensile (Gr - Fig. 5)

Die vermoë om iets te kan vasknyp, byvoorbeeld tussen twee podomere van die maksilla. Die term van taksonomiese belang by Chonopeltis spesies.

Hepatopankreas: hepatopancreas/digestive gland Verteringsklier geleë in die karapaks en sluit by spysverteringskanaal aan net voor die krop.

Interokkulere afstand (D - Fig. 13)

Die afstand tussen die middelpunt van die saamgestelde oë.

Karapaks: carapace (Ka - Fig. 1, 2, 3 \& 4)

'n Skild versterk met chitien wat die liggaam dorsaal bedek. Die karapaks word gevorm deur die bedekking oor die sefalon plus twee sefaliese lobbe wat posteriorwaarts verloop.

Karapaksbreedte (E - Fig. 13)

Die afstand oor die breedste deel van die karapaks.

Karapakslengte ( $\mathrm{B}$ - Fig. 13)

Afstand tussen die anteriorrand van die karapaks en die punte van die karapakslobbe. Die afstand word oor die kortste moontlike afstand gemeet.

Karapaksspleetlengte (C - Fig. 13)

Die lengte van die spleet in die karapaks.

Koker: semen capsule/socket apparatus/socket (Ko - Fig. 11)

Sakagtige struktuur met posterioropening, wat dorsaalwaarts gerig is, op die protopodiet van die derde swempoot van Argulus- en Chonopeltis-mannetjies.

Koksopodiet: coxopodite

Kyk swempoot.

Krop: crop

Sakagtige uitstulping van die spysverteringskanaal. Dit volg op die esofagus.

Labiaalstekel: labial spine (Lst - Fig. 12)

Gepaarde kruikvormige uitsteeksels op die metastoom van die proboscis.

Labrum/bo-lip/voorlip: (La - Fig. 12)

Die bedekking wat oor die anteriorgedeelte van die mond strek.

Larvaalstadium: larval stage

'n Stadium in die ontwikkeling van 'n larwe.

Maksilla: maxillae (Ma - Fig. 1, 3 \& 4)

Vierde aanhangsel van die sefalon. In die negentiende-eeuse literatuur somtyds maksillipeed genoem.

\section{Maksillastekels}

Eerste maksillastekel: maxillary spine/accessory spine of maxilla (Ms - Fig. 1 \& 3)

Voorste paar posteriorgerigte stekels geleë tussen die basaalpodomere van die maksillas.

Tweede maksillastekel: second maxillary spine, sternal spine (Mst - Fig. 1 \& 3) 


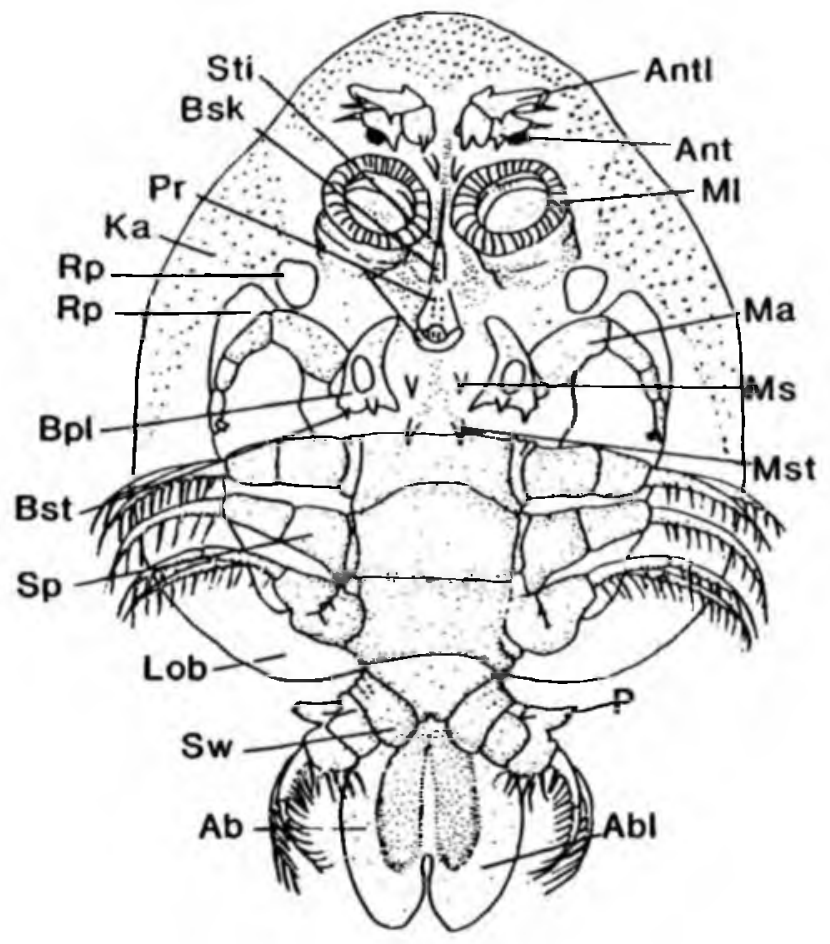

FIGUUR 1: Argulus japonicus, ventraalaansig.

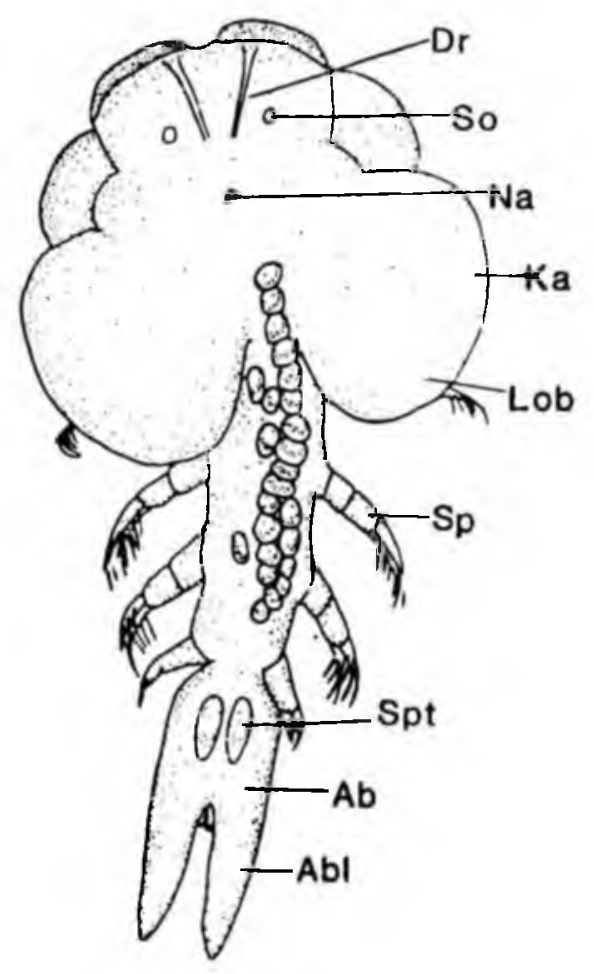

FIGUUR 2: Chonopeltis-spesie, dorsaalaansig.

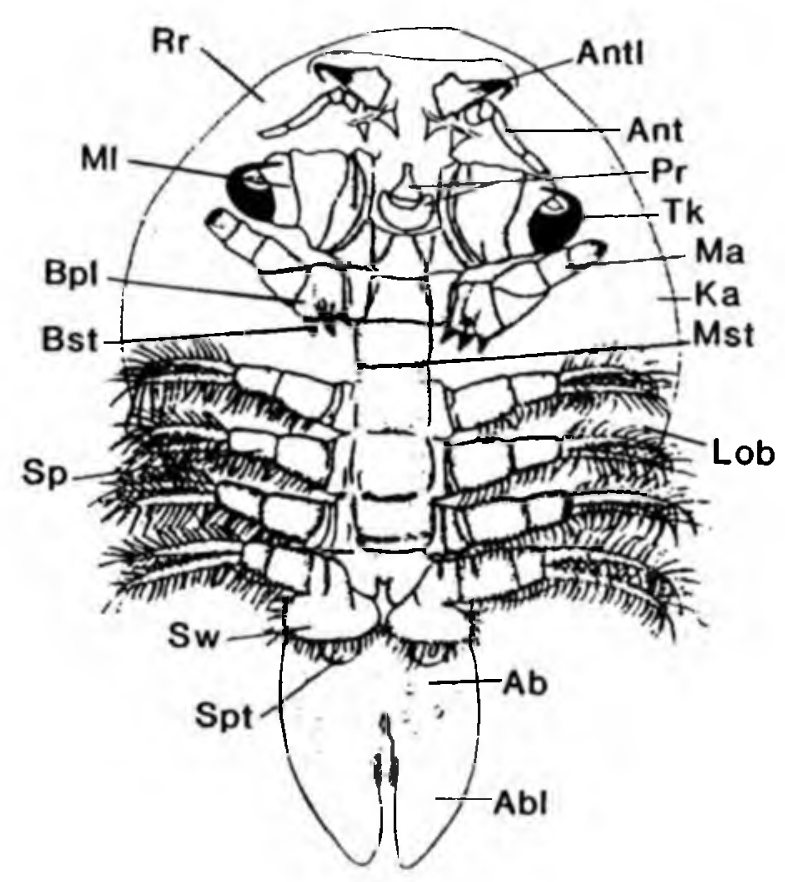

FIGUUR 3: Dolops ranarum, ventraalaansig.

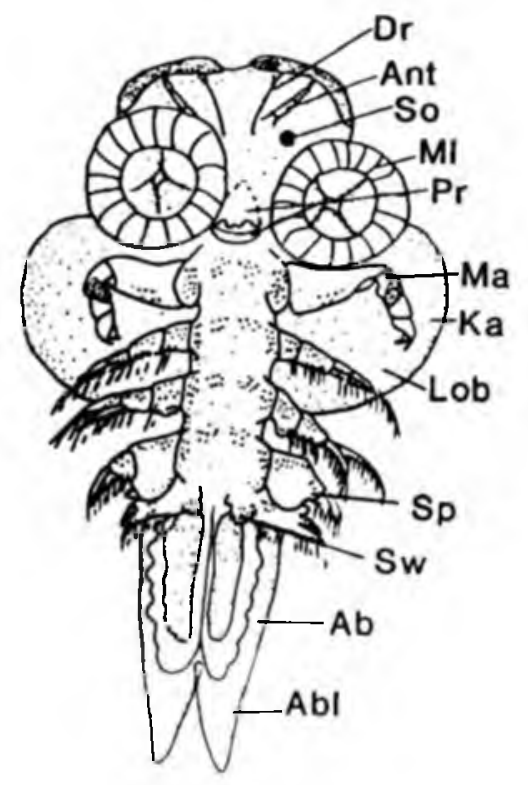

FIGUUR 4: Chonopeltis-spesies, ventraalaansig.

Verklaring van simbole: $\mathrm{Ab}$ - abdomen, $\mathrm{Abl}$ - abdomenlob, Ant - antenne, Antl - antennule, Bpl basaalplaat, Bsk - basaalskede, Bst - basaalstekel, $\mathrm{Dr}$ - dorsaalrif, $\mathrm{Fr}$ - furkaalramus, $\mathrm{Ka}$ - karapaks, Lob - sefaliese lob, Ma - maksilla, Ml maksillula, Ms - eerste maksillastekel, Mst - tweede maksillastekel, $\mathrm{Na}$ - nauplius oog, $\mathrm{P}$ - chitienpen, $\operatorname{Pr}$ - proboscis, $\mathrm{Rp}$ - respirasiestreek, $\mathrm{Rr}$ - riffelrand, So - saamgestelde oog, Sti - stilet, $\mathrm{Sp} \mathrm{-}$ swempoot, Spt - spermateka, Sw - swemlob. 


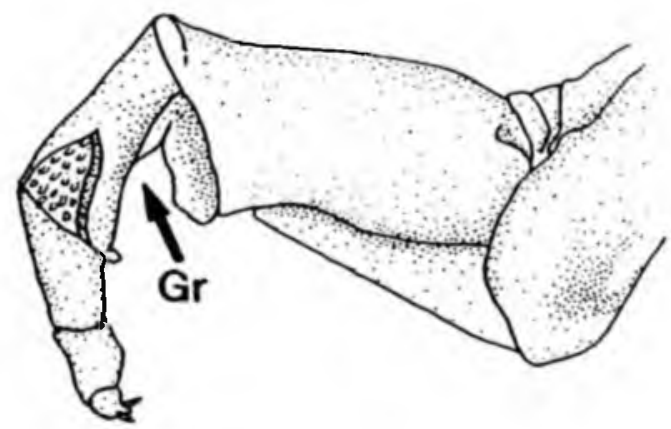

FIGUUR 5. Maksilla van Chonopeltis-indiwidu.

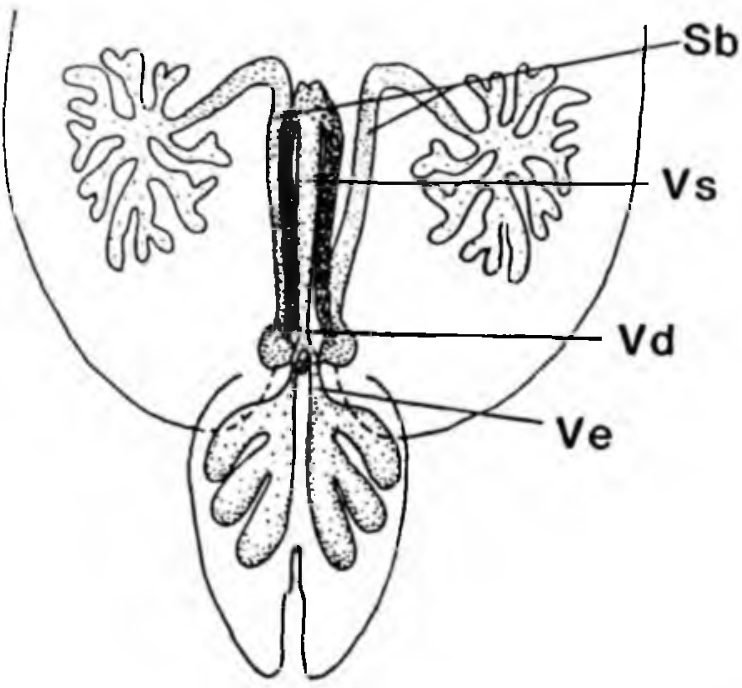

FIGUUR 6. Manlike geslagstelsel van ranarum-indiwidu.

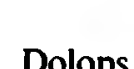

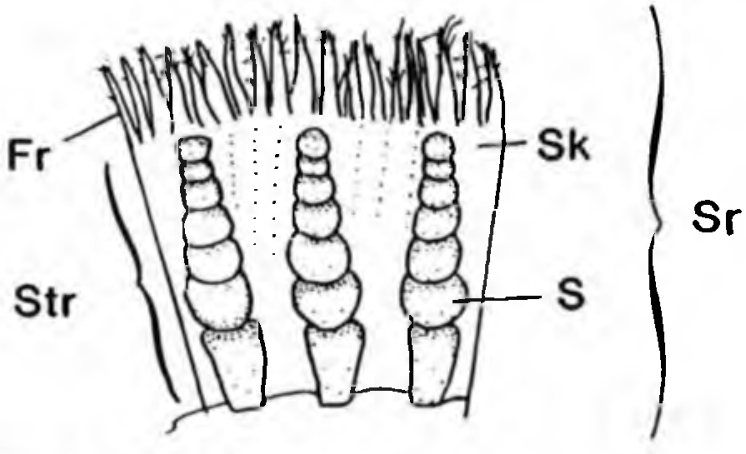

FIGUUR 8. Suierkraag.

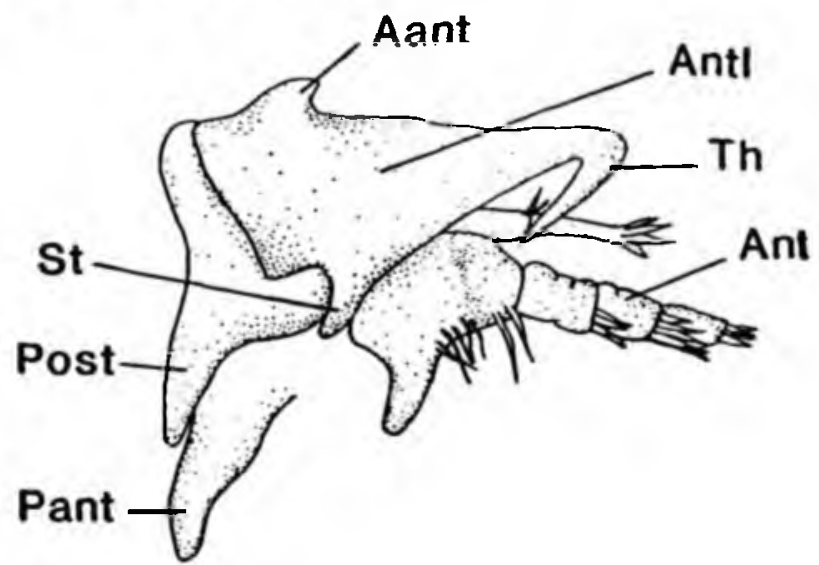

FIGUUR 9. Antennule en antenne van Argulus japonicus-indiwidu.

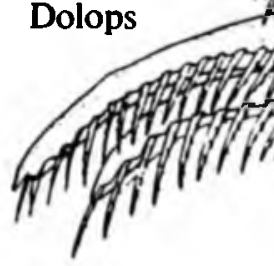

FIGUUR 10. Eerste en tweede swempoot van Dolops ranarum-indiwidu om flagellums aan te toon.

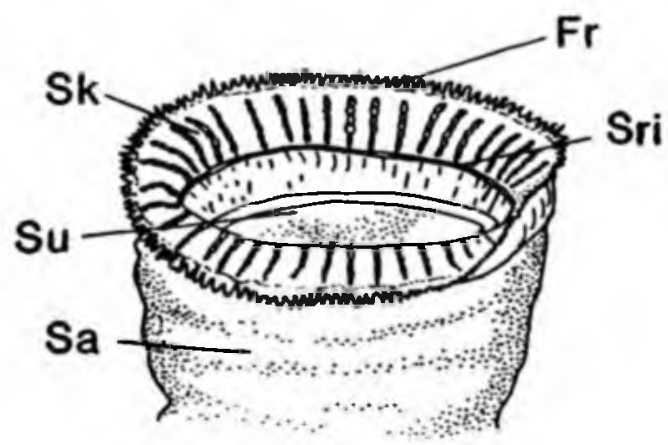

FIGUUR 7. Suier/maksilla van Argulus japonicusindiwidu.

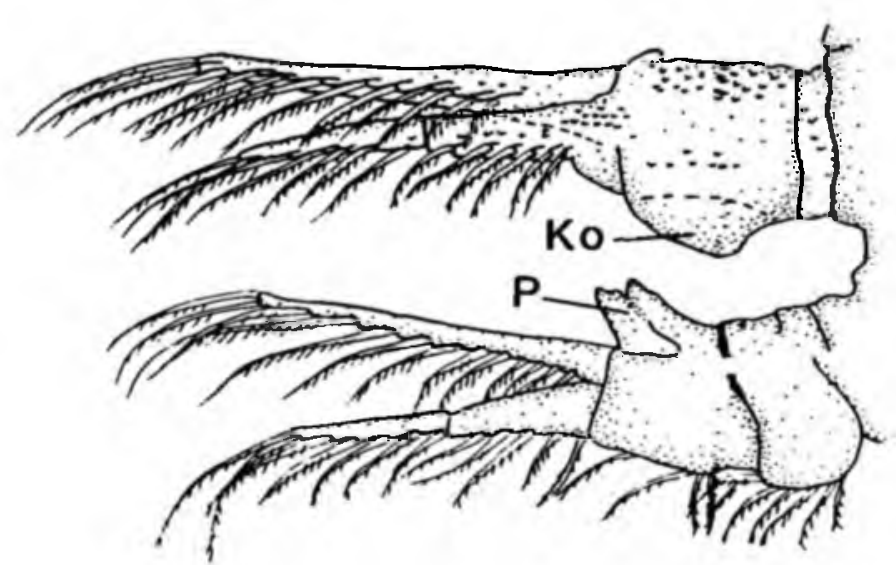

FIGUUR 11. Derde en vierde swempoot van Argulus japonicus-indiwidu om pen-en-koker-struktuur aan te toon. 


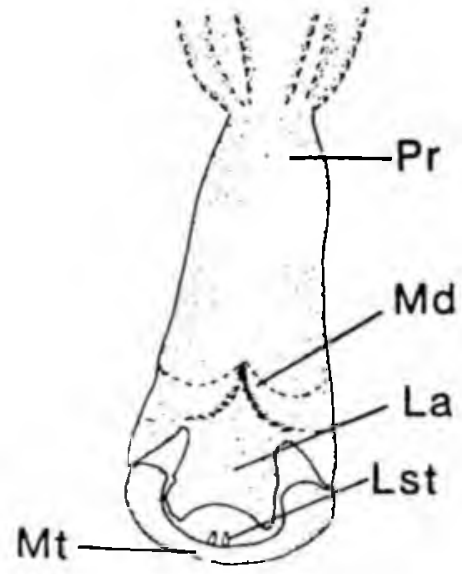

FIGUUR 12. Proboscis van Argulus japonicusindiwidu. Mandibels in stippellyn aangedui.

Verklaring van simbole: Ab - abdomen, Aant anterior antennule stekel, Ant - antenne, Antl antennule, $\mathrm{Fl}$ - flagellum, $\mathrm{Fr}$ - fraiingrand, $\mathrm{Gr}$ grypende aanhangsel, Ko - koker, La - labrum, Lst - labiaalstekel, Md - mandibel, Mt - metastoom, P - chitienpen, Pant - post-antennestekel, post posterior antennestekel, $\mathrm{Pr}$ - proboscis, S - skleriet, $\mathrm{Sa}$ - suieraanleg, $\mathrm{Sb}$ - spermatoforiese buis, Sk suierkraag, Sri - suierring, St - mediaalstekel (antennule), Str - sklerietstraal, Su - suier, Th terminaalhaak van antennule, $\mathrm{Vd}-$ vas deferens, $\mathrm{Ve}$ - vas efferens, Vs - vesikula seminalis.

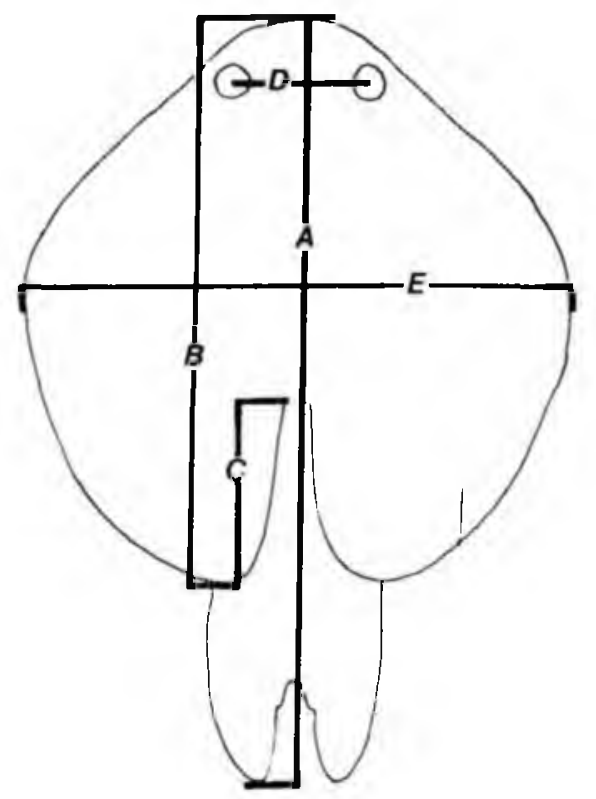

FIGUUR 13: Dorsaalaansigskets van 'n verteenwoordiger van die Branchiura om aan te toon hoe morfometriese afmetings geneem word.

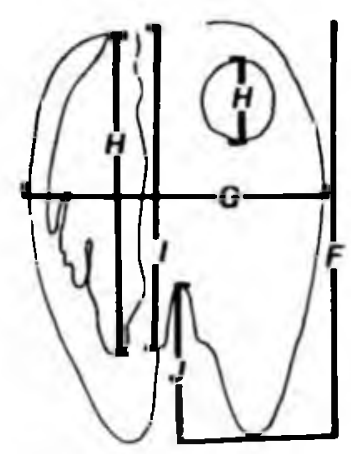

FIGUUR 14: Dorsaalaansigskets van die abdomen van 'n verteenwoordiger van die Branchiura om aan te toon hoe die morfometriese afmetings geneem word. Aan die linkerkant is testes en aan die regterkant 'n spermateka aangetoon.

Verklaring van simbole: A - totaallengte, B karapakslengte, $\mathbf{C}-$ karapaksspleetlengte, $\mathbf{D}-$ interokkulère afstand, E - karapaksbreedte, $\mathbf{F}$ - abdomenlengte, $\mathrm{G}$ - abdomenbreedte, H spermateka-/testeslengte, I - afstand tot by furkaalramus, $\mathbf{J}$ - abdomenspleetlengte.

Agterste paar posteriorgerigte stekels geleë op posteriorrand van sefalon. Soms torakaalstekels genoem.

Maksillula (eerste maksilla): maxillula/first maxilla (Ml - Fig. 1, 3 \& 4)

Derde aanhangsel aan die sefalon. By Dolops-spesies is dit omvorm tot 'n kragtige haak. Argulus- en Chonopeltis-larwes broei uit met 'n haak, maar dit omvorm tot 'n suier voor volwassenheid.

Mandibels: mandibels (Md - Fig. 12)

Gepaarde aanhangsels in die proboscis.

Mediaalstekel: medial spine/ventral spine (St - Fig. 9)

Postero-ventraalstekel van antennule.

Mediaanoog: median eye/median ocellus

Kyk enkelvoudige oog.

Metastoom/onderlip/agterlip (Mt - Fig. 12)

Die tweelobbige lip van Crustacea. Dit bedek mondopening posterior.

Nauplius oog: nauplius eye

Kyk enkelvoudige oog.

Pasuitgebroeide larwes: newly hatched larvae

Die lewensvorm wat uit die eier te voorskyn kom. Sommige Argulus-spesies het 'n naupliuslarwe, terwyl Dolops-larwes soos jong volwassenes lyk.

Periferaal seta

Seta op rand van die karapaks. Dunner en dikker seta kom voor.

Persentasie besmetting (\%B): prevalence

Aantal gashere (b) wat besmet is met minstens een parasiet gedeel deur die aantal gashere wat in die steekproef deursoek is (n). Dit kan ook as 'n persentasie uigedruk word deur bogenoemde breuk met 100 te vermenigvuldig. 


$$
\begin{aligned}
& \frac{b}{n}=B \text { (besmettingsfaktor) } \\
& \text { of } \frac{b}{n} \times 100=\% B \text { (persentasie besmetting) }
\end{aligned}
$$

\section{Pigmentvlekke: pigment spots}

Bedek veral die geslagstelsels van sowel die mannetjie as die wyfie. Dit is afwesig by Chonopeltis-spesies wat in die kieue voorkom.

Podomeer/lit: podomere

'n Segment van 'n aanhangsel.

Post-antennestekel: medial spine/mesial spine/post antennal spine (Pant - Fig. 9)

Uitsteeksels wat posterior van die antennulestekel en mediaal van die antennestekel gelee is.

Posterior antennestekel: posterior spine (Post - Fig. 9)

Posterior uitsteeksel op basaalpodomeer van antenne.

Prekoksopodiet: precoxopodite

Kyk swempoot en protopodiet.

Proboscis: proboscis/mouth tube (Pr - Fig. 1, 3, 4 \&

12)

Ventrale silindriese uitgroeisel van die sefalon bestaande uit metastoom plus labrum. Die mond kom hierbinne voor.

Protopodiet: protopodite

Kyk ook swempoot.

Proksimaalgedeelte van die aanhangsel. Dit bestaan uit koksopodiet en basipodiet en soms ook prekoksapodiet.

Respirasiestreek: respiratory area (Rp - Fig. 1)

Verdunde streek op die ventraalgedeelte van die karapaks. Dit word vir respirasie gebruik. Die vorm van respirasie-area is dikwels van taksonomiese belang.

Riffelrand (Rr - Fig. 3)

'n Smal, onreëlmatige band wat ventraal op die periferie van die anterior en anterolateraalgedeelte van die karapaks van Dolops-indiwidue voorkom.

Saamgestelde oog: compound eye (So - Fig. 2 \& 3) Orgaan vir sig. Saamgestel uit aantal kegelvormige lense.

Sefalon: cephalon/cephalic area

Anterior tagma van die liggaam waarop oe, antennules, antennes, maksillulas, maksilla en proboscis met mandibels voorkom.

Sefaliese lob/lateraallob/karapakslob: cephalic lobe/lateral lobe/carapace lob (Lob - Fig. 1, 2, 3 \& 4)

Kyk ook sefalon.

Deel van die karapaks, bestaan uit twee lobbe wat posteriorwaarts verloop.

Seta: seta/hair

Haaragtige lang, dun uitgroeisels op die swempote. 'n Duidelike setabasis kom voor. Drie tipes kan onderskei word, naamlik: gekam (combed), geveer (serrated) en eenvoudig (simple).

Skubbe/tandskubbe: scales/denticles

Plat, verharde strukture wat op die ventraalop- pervlak voorkom. Soms het die skubbe 'n getande rand en staan bekend as tandskubbe, soms slegs een of meer uitsteeksels.

Spermateka: spermatheca (Spt - Fig. 2 \& 3)

'n Paar sakagtige organe in die abdomen van wyfies waarin sperme gestoor word. Spermateka is deur die spermatekabuis verbind aan spermatekastekels waarin spermateka-openinge voorkom.

Spermatekabuis: spermatecal duct

Kyk spermateka.

Spermatekastekel: spermathecal spine

Kyk spermateka.

Spermatofoor: spermatophore

'n Kapsel van albumienagtige materiaal waarin sperme oorgedra word. Kom slegs by verteenwoordigers van die genus Dolops voor.

Spermatoforiese buis: prostate ampullae/blind capsule/spermatoforic glands/blindending tube ( $\mathrm{Sb}$ Fig. 6)

Buis waarin die vloeistof, wat later die spermatofoorwand vorm, gestoor word.

Stilet: poison spine/pre-oral spine/pre-oral sting/sting (Sti - Fig. 1)

Skerp, gepunte stekel anterior van die proboscis by Argulus. Stilet kan terugtrek in basaalskede (Bsk).

Suier: sucking disc/sucker (Su - Fig. 7)

Maksillula van volwasse Chonopeltis- en Argulusindiwidue. Dit is omvorm tot 'n orgaan waarin 'n vakuum bewerkstellig kan word en word gebruik vir vashegting. Dit bestaan uit 'n suieraanleg (Sa) plus suierrand $(\mathrm{Sr})$.

Suierkraag/suierrand: belt/margin of sucker/border/rim (Sk - Fig. 7 \& 8)

Word gevorm deur 'n suierring (Sri) mediaan en fraiingrand $(\mathrm{Fr})$ op die periferie. Tussen-in gevul deur sklerietstrale (Str) met skleriete (S).

Swemlob: natatory lobe (Sw - Fig. 1, 3 \& 4)

Plat, skyfvormige vergroting van basaalpodomeer van die vierde paar swempote, posterior verleng.

Swempoot: swimming leg/natatory leg/thoracic appendage (Sp - Fig. 1, 3 \& 4)

Kyk ook protopodiet.

Twee-assige aanhangsels van toraks. Vier paar aanwesig by alle verteenwoordigers van die Branchiura. Dit bestaan uit 'n protopodiet wat oorsprong gee aan endo- en eksopodiete.

Tagma: tagma

Hoofafdeling van die liggaam. Dit is saamgestel uit 'n variërende getal somiete.

Terminaalhaak van antennule: antennulary spine/ apical spine/lateral spine/terminal spine (Th - Fig. 9)

Lateraalgelee haak van antennule. By Dolops-indiwidue is dit die tweede podomeer.

Terminaalklou: claw (Tk - fig. 3)

Dit is die distale klou op ' $n$ aanhangsel, bv. die maksillula van Dolops. Dit bestaan uit die derde en vierde podomeer van die maksillula.

Terminaalpodomeer:

Die distale podomeer van elke liggaamsaanhangsel.

Torakaalstekels: thoracic spine.

Kyk maksillastekels. 
Die stekels geleë in die gebied tussen die maksillula en die eerste paar torakale aanhangsels. By Argulus is twee paar aanwesig en staan bekend as maksillastekels, terwyl Dolops slegs een paar besit, waarna daar meestal as torakaalstekels verwys word.

\section{Toraksaanhangsel}

Kyk swempoot.

\section{Tregterstruktuur}

Tregtervormige induiking op die lateraalkant van die onbevrugte eier van Chonopeltis-indiwidue.

Ontwikkelingstyd: hatching time

Die tydperk vanaf eierlegging totdat die eerste larwe uitbroei.

Uterus: uterus/egg sac

Stoorplek van onbevrugte eiers in toraks van wyfies. Vas deferens-/deferente geslagsbuis: vas deferens (Vd - Fig. 6)

Buis vanaf vesicula seminalis na geslagsopening, verloop posteriorwaarts.

Vas efferens-/efferente geslagsbuis: vas efferens (Ve - Fig. 6)

Buis vanaf testes na vesicula seminalis, verloop anteriorwaarts.
Vesikula seminalis/spermreservoir: vesicula seminalis/sperm reservoir (Vs - Fig. 6)

Mediaangelee buis in toraks. Vasa efferensia open hierin en vasa deferensia het hulle oorsprong hieruit. Voorkeurposisie:

Die posisie wat deur die parasiet op die gasheer geselekteer word vir vashegting. Tydens hiperinfeksie word geen voorkeurposisie onderskei nie.

\section{LITERATUURVERWYSINGS}

1. Fryer, G. (1968). The parasitic Crustacea of African freshwater fishes; their biology and distribution, J. Zool. (Lond.), 156, 45-95.

2. Fryer, G. (1969). A new freshwater species of the genus Dolops (Crustacea: Branchiura) parasitic on a Galaxiid fish of Tasmania - with comments on disjunct distribution patterns in the Southern hemisphere, Austr. J. Zool., 17, 49-64.

3. Ringuelet, R. (1943). Revision de los Argúlidos Argentinos (Crustacea: Branchiura) con el catálogo de las especies neotropicales, Revta Mus. La Plata (Sec. Zool.), 3, 43-99.

4. Stuhlmann, F. (1891). Zur Kenntniss der Fauna centralafrikanischer Seen II. Ueber eine neue Art der Arguliden Gattung Gyropletis, Zool. Jb. (Syst.), 5, 152-154 + plaat 1, 3, 4 \& 9.

5. Van As, J.G. (1986). A new species of Chonopeltis (Crustacea: Branchiura) from the Limpopo system, southern Africa, $S$. Afr. Tydskr. Dierk.,21(4), 348-351. 